\title{
Analisis Volatilitas Cryptocurrency, Emas, Dollar, dan Indeks Harga Saham Gabungan (IHSG)
}

\author{
Oey Laurensia Dewi Warsito* \\ 1,2 Fakultas Ekonomika dan Bisnis Universitas Kristen Satya Wacana Salatiga
}

\section{A R T I C L E IN F O}

Article history:

Received 01 December 2019

Received in revised form

31 December 2019

Accepted 15 January 2020

Available online 26

February 2020

\section{Kata Kunci:}

Cryptocurrency, Emas,

Dollar Index, Indeks Harga

Saham Gabungan (IHSG),

Volatilitas, GARCH

Keywords:

Cryptocurrency, Gold, Dollar Index, Composite Stock

Prices Index in the Indonesia

Stock Exchange (IDX),

Volatility, GARCH.

\begin{abstract}
A B S T R A K
Penelitian ini dilakukan untuk menganalisis volatilitas cryptocurrency. Variabel emas, Dollar Index, dan Indeks Harga Saham Gabungan (IHSG) digunakan sebagai variabel bebas. Objek cryptocurrency dalam penelitian ini adalah Bitcoin dan Ethereum yang memiliki kapitalisasi pasar terbesar. Data pada penelitian ini menggunakan periode 1 Januari 2017 hingga 31 Desember 2019. Penelitian ini menggunakan analisis GARCH. Hasil penelitian ini menunjukkan bahwa volatilitas Bitcoin dan Ethereum tidak dipengaruhi oleh variabel lain, namun dipengaruhi oleh harga dari masing-masing Bitcoin dan Ethereum pada harga masa lalu. Hal ini menunjukkan bahwa pasar cryptocurrency merupakan pasar yang tidak efisien.
\end{abstract}

\section{A B S T R A C T}

This research was conducted to analyze cryptocurrency volatility. Gold, Dollar Index, and Composite Stock Prices Index in the Indonesia Stock Exchange (IDX) variable are used as independent variables. The cryptocurrency objects in this study are Bitcoin and Ethereum which have the largest market capitalization. The data used in this study is from $1^{\text {st }}$ January 2017 to $31^{\text {st }}$ December 2019. This study uses GARCH analysis. The result of this study indicates that the volatility of Bitcoin and Ethereum is not influenced by other variables, but it is influenced by the prices of each Bitcoin and Ethereum at past prices. This shows that the cryptocurrency market is an inefficient market.

\footnotetext{
* Corresponding author.

E-mail addresses: oeylaurensiadewiwarsito@gmail.com (Laurensia Dewi Warsito Oey)
} 


\section{Pendahuluan}

Kemajuan dalam bidang teknologi telah mencapai sektor keuangan. Salah satunya adalah dengan munculnya mata uang kripto dengan menggunakan teknologi kriptografi atau sering disebut cryptocurrency. Mata uang kripto telah muncul sejak tahun 2008 ditemukan oleh sekelompok orang tidak dikenal yang diberi nama Satosi Nakamoto. Mata uang kripto atau cryptocurrency yang artinya sebuah manifestasi dari adanya perkembangan sebuah teknologi yang memiliki serangkaian kode kriptografi. Kode tersebut dapat dibentuk sehingga kode tersebut dapat disimpan dalam sebuah perangkat komputer (Robiyanto et al., 2019). Selain itu kelebihan dalam mata uang kripto adalah dapat dipindah tangankan seperti dalam surat elektronik untuk melakukan pembayaran dalam suatu transaksi (Yohandi et al., 2017). Dalam transaksi mata uang kripto sangat sulit dipalsukan atau dimanipulasi karena memiliki keamanan yang sangat baik (Bhosale \& Mavale, 2018). Pasar kripto mengalami perkembangan yang sangat baik hingga sekarang, kapitalisasi pasar yang dimilikinya sangat besar. Sehingga diyakini bahwa pasar kripto sendiri dapat membantu investor dalam mencari imbal hasil yang besar. Penelitian ini akan membahas mata uang kripto dalam Bitcoin dan Ethereum.

Bitcoin adalah salah satu jenis cryptocurrency yang sering digunakan oleh masyarakat di negaranegara maju. Bahkan di Indonesia, sudah menjadi alat investasi meskipun belum dapat digunakan sebagai sarana pembayaran karena belum diakui sebagai instrument pembayaran yang sah di Indonesia. Menurut Ausop (2018) Bitcoin memiliki beberapa keunggulan. Keunggulan paling utamanya adalah teknologi Blockchain. Namun, di samping keunggulan itu, terdapat beberapa kelemahan antara lain bahwa uang virtual Bitcoin tidak memiliki aset yang mendasari (underlaying asset), tidak dikontrol oleh lembaga otoritas yang bertanggung jawab (di Indonesia oleh Otoritas Jasa Keuangan/ OJK) sehingga tidak aman, serta tanpa nama jelas pemiliknya sehingga rawan dijadikan sarana kejahatan. Nilai Bitcoin naik dan turun berdasarkan hukum kebutuhan pasar dan penawaran. Ketika Bitcoin yang beredar hanya sedikit untuk memenuhi kebutuhan sedangkan permintaan banyak, nilai harga Bitcoin akan naik. Pada dasarnya Ethereum sama dengan Bitcoin, namun mereka memiliki perbedaan dalam tujuan dan fungsi. Bitcoin memfokuskan dalam men-transfer uang elektronik secara peer-to-peer. Sedangkan Ethereum dapat digunakan untuk menjalankan aplikasi apapun, termasuk transfer uang elektronik dalam bentuk Ether maupun token Ethereum lain.

Sebelum melakukan investasi, investor perlu mengetahui tingkat pengembalian atau imbal hasil dan tingkat resiko. Analisis volatilitas mampu membantu investor dalam mengenali tingkat resiko. Selain itu, analisis volatilitas berguna dalam pembentukan harga, pembentukan portofolio dan manajemen resiko. Dengan begitu analisis volatilitas mampu membantu investor dalam mengambil sebuah keputusan. Pada saat nilai volatilitas tinggi maka investor akan seberusaha mungkin menjual asetnya guna meminimalkan resiko. Namun pada saat volatilitas tinggi hal tersebut menunjukkan jika harga akan mengalami naik dan turun yang sangat cepat. Sehingga memberikan kesempatan untuk dapat mendapatkan tingkat pengembalian dan resiko yang tinggi. Sebaliknya, jika nilai volatilitas rendah, peluang dalam mengambil tingkat pengembalian secara cepat akan kecil. Sehingga biasanya akan dilakukan dalam jangka waktu yang panjang agar dapat memperoleh tingkat pengembalian yang diinginkan. Hal tersebut dalam istilah keuangan biasa disebut "high risk high return".

Analisis volatilitas akan diuji dengan menggunakan sistem GARCH, karena sistem kerangka kerja dari GARCH di rasa sangat cocok untuk digunakan. GARCH biasa digunakan dalam analisis seperti tingkat pengembalian dan volatilitas. Kerangka kerja GARCH dapat memberikan sesuatu yang sensitif terhadap aset yang akan diukur, seperti dalam penelitian ini adalah cryptocurrency khususnya Bitcoin dan Ethereum. Selain itu, penelitian ini menggunakan model GARCH karena memiliki kelebihan dibandingkan model lainnya. Model GARCH tidak melihat heteroskedastisitas sebagai suatu masalah, namun memanfaatkannya untuk membuat sutu model. Selain itu dalam model ini tidak hanya menghasilkan peramalan dari Y saja, tetapi juga peramalan dari varians. Penelitian mengenai analisis volatilitas telah banyak dilakukan dalam meneliti sebuah aset, seperti yang dilakukan oleh Nastiti dan Suharsono (2012) menganalisis volatilitas terhadap saham perusahaan go public. Penelitian lainnya dilakukan oleh Hartati \& Saluza (2017) meneliti tentang analisis volatilitas pada bidang keuangan. Selain dalam bidang keuangan penelitian analisis volatilitas pada bidang agrikultur khususnya pada kopi telah dilakukan oleh Rahayu, Chang, \& Anindita (2015). Pada tahun yang sama, Dyhrberg yang melakukan penelitian analisis volatilitas pada Bitcoin, emas, dan dollar. Pada penelitian selanjutnya Bhosale \& Mavale (2018) meneliti pada analisis volatilitas dalam cryptocurrency.

Menurut Nurmapika (2018) Volatilitas pada dasarnya adalah fenomena alamiah. Di Indonesia sebagai salah satu negara berkembang rentan terhadap volatilitas harga pangan. Hal ini dikarenakan sebagai kebutuhan pangan pokok masih diimpor, sehingga jika harga pangan dunia tidak stabil akan berpengaruh terhadap kondisi harga pangan dalam negeri. Penelitian analisis volatilitas telah banyak 
dilakukan. Namun terhadap penelitian yang membahas analisis volatilitas dalam cryptocurrency, emas, dollar, dan Indeks Harga Saham Gabungan (IHSG) belum pernah dilakukan. Sehingga penelitian ini membahas analisis volatilitas pada cryptocurrency khususnya Bitcoin dan Ethereum, emas, dollar, dan Indeks Harga Saham Gabungan (IHSG) dengan menggunakan sistem GARCH. Tujuan yang ingin dicapai dalam penelitian ini adalah untuk menganalisis volatilitas pada cryptocurrency khususnya Bitcoin dan Ethereum, emas, Dollar Index, dan Indeks Harga Saham Gabungan (IHSG).

Penelitian ini diharapkan dapat memberikan manfaat bagi para pembuat kebijakan untuk dapat mengetahui manfaat mendasar yang dimiliki oleh Bitcoin dan Ethereum dalam hal investasi. Selain itu, agar penelitian ini dapat menjadi bahan pertimbangan dalam pengambilan keputusan investasi.

\section{Metode}

Metode yang akan digunakan dalam penelitian ini adalah metode kuantitatif. Data yang digunakan dalam penelitian ini bersumber dari investing.com yang berarti bahwa penelitian ini menggunakan data sekunder. Lalu data akan dianalisis menggunakan uji unit root test dan metode GARCH.

Penelitian ini menggunakan lima variabel Bitcoin, Ethereum, emas, Dollar Index, dan Indeks Harga Saham Gabungan (IHSG). Data yang digunakan adalah harga penutup periode 1 Januari 2017 hingga tanggal 31 Desember 2019. Data Bitcoin, Ethereum, emas, dan Dollar Index dalam bentuk mata uang Dollar dikarenakan dapat diperdagangkan dalam bentuk berjangka di Indonesia dengan menggunakan fixed exchange rate yaitu sebesar Rp 10.000,00. Dan Indeks Harga Saham Gabungan (IHSG) dalam bentuk Rupiah.

Dalam penelitian ini menggunakan dua model perhitungan untuk menyelidiki kesamaan antara Bitcoin, emas, Dollar Index, dan IHSG serta Ethereum, emas, Dollar Index, dan Indeks Harga Saham Gabungan (IHSG) dengan variabel penjelas dan mean equation (1), dan variance equation (2) seperti yang disajikan dibawah ini:

\section{A. Bitcoin}

$\Delta$ nnprice $\mathrm{BTC}_{\mathrm{B}}=$

$$
\beta_{0}+\beta_{1} \text { lnprice }_{t-1}+\beta_{2} \text { Gold }_{t-1}+\beta_{0} D X Y_{t-1}+\beta_{4}{ }_{1 H S G_{t-1}}+\varepsilon_{t}
$$

$\sigma_{t}^{2} \mathrm{BTC}=$

$\exp \left(\lambda_{0}+\lambda_{1}\right.$ Gold $\left._{t-1}+\lambda_{2} D X Y_{t-1}+\lambda_{a} I H S G_{t-1}\right)+a \varepsilon_{t-1}^{2}+\beta_{\sigma_{t}^{2}-1}$

\section{B. Ethereum}

$\Delta$ lnprice $\mathrm{E}_{\mathrm{t}} \mathrm{ETH}=$

$$
\begin{aligned}
& \beta_{0}+\beta_{1} \text { Lnprice }_{t-1}+\beta_{2} \text { Gold }_{t-1}+\beta_{2} D X Y_{t-1}+\beta_{4} I H S G_{t-1}+\varepsilon_{t} \\
& \sigma_{t}^{2} \text { ETH }= \\
& \exp \left(\lambda_{0}+\lambda_{1} \text { Gold }_{t-1}+\lambda_{2} D Y_{t-1}+\lambda_{1} I H S G_{t-1}\right)+a \varepsilon_{t-1}^{2}+\beta_{\sigma_{t}-1}
\end{aligned}
$$

\section{Hasil dan Pembahasan}

Setelah melakukan uji stasioneritas data, selanjutnya uji GARCH dilakukan. Pada data harga harian untuk menyelidiki volatilitas Bitcoin dan Ethereum dengan variabel penjelas masa lalu, emas, Dollar Index, dan Indeks Harga Saham Gabungan (IHSG). 
Table 1. GARCH dengan variabel penjelas dan mean equation dalam Bitcoin

\begin{tabular}{lllll}
\hline Variabel & Coefficient & Std. Error & z-Statistik & Probabilitas \\
\hline C & $1.32 \mathrm{E}-05$ & $2.35 \mathrm{E}-06$ & 5.609933 & 0.000000 \\
Bitcoin (BTC) ln price $_{\mathrm{t}-1}$ & 0.113109 & 0.000120 & 945.4099 & 0.000000 \\
Emas (XAU) price $_{\mathrm{t}-1}$ & $-7.04 \mathrm{E}-07$ & $2.88 \mathrm{E}-07$ & -2.440809 & 0.0147 \\
Dollar Index (DXY) price $_{\mathrm{t}-1}$ & $-9.24 \mathrm{E}-06$ & $9.27 \mathrm{E}-06$ & -0.996187 & 0.3192 \\
IHSG price $_{\mathrm{t}-1}$ & $8.70 \mathrm{E}-09$ & $4.00 \mathrm{E}-08$ & 0.217427 & 0.8279 \\
\hline Variance Equation & & & & \\
\hline $\mathrm{C}$ & $9.73 \mathrm{E}-11$ & $5.64 \mathrm{E}-11$ & 1.724935 & 0.0845 \\
RESID(-1)^2 & 0.488703 & 0.037855 & 12.90992 & 0.0000 \\
GARCH(-1) & 0.709231 & 0.016152 & 43.90923 & 0.0000 \\
\hline R-squared & 0.989289 & Mean dependent var & 0.000380 \\
Adjusted R-squared & 0.989213 & S.D. dependent var & 0.006113 \\
S.E. of regression & 0.000635 & Akaike info criterion & -13.71065 \\
Sum squared resid & 0.000287 & Schwarz criterion & -13.65322 \\
Log likelihood & 4924.268 & Hannan-Quinn criter. & -13.68848 \\
Durbin-Watson stat & 2.06542 & & & \\
\hline
\end{tabular}

Berdasarkan Tabel 1, hasil analisis menunjukkan dengan alfa 5\% diperoleh bahwa return Bitcoin dipengaruhi oleh harga sebelumnya yaitu pada harga Bitcoin $\ln _{\mathrm{t}-1}$ dan harga emas $\mathrm{t}_{\mathrm{t}-1}$. Namun pada variabel harga Dollar Index $\mathrm{t}_{\mathrm{t}-1}$ dan harga IHSG $_{\mathrm{t}-1}$ tidak mempengaruhi return Bitcoin. Selain itu, penelitian ini mengikuti model GARCH, dibuktikan dengan hasil GARCH (-1) kurang dari 5\%.

Table 2. GARCH dengan variabel penjelas dan mean equation dalam Ethereum.

\begin{tabular}{lllll}
\hline Variabel & Coefficient & Std. Error & z-Statistik & Probabilitas \\
\hline C & $7.68 \mathrm{e}-05$ & $1.60 \mathrm{E}-05$ & 4.805446 & 0.000000 \\
Ethereum (ETH) ln price $\mathrm{t}_{-1}$ & 0.186908 & 0.000430 & 434.5627 & 0.000000 \\
Emas (XAU) price $_{\mathrm{t}-1}$ & $1.63 \mathrm{E}-06$ & $2.06 \mathrm{E}-06$ & 0.793529 & 0.4275 \\
Dollar Index (DXY) price $_{\mathrm{t}-1}$ & $-7.01 \mathrm{E}-05$ & $5.70 \mathrm{E}-05$ & -1.230231 & 0.2186 \\
IHSG price $_{\mathrm{t}-1}$ & $-3.06 \mathrm{E}-07$ & $2.42 \mathrm{E}-07$ & -1.260582 & 0.2075 \\
\hline Variance Equation & & & & \\
\hline $\mathrm{C}$ & $3.41 \mathrm{E}-09$ & $1.65 \mathrm{E}-09$ & 2.066333 & 0.0388 \\
RESID(-1)^2 & 0.363923 & 0.029504 & 12.33471 & 0.0000 \\
GARCH(-1) & 0.755398 & 0.011861 & 63.68745 & 0.0000 \\
\hline R-squared & 0.904331 & Mean dependent var & 0.001276 \\
Adjusted R-squared & 0.903658 & S.D. dependent var & 0.014895 \\
S.E. of regression & 0.004623 & Akaike info criterion & -10.60005 \\
Sum squared resid & 0.015197 & Schwarz criterion & -10.54262 \\
Log likelihood & 3809.119 & Hannan-Quinn criter. & -10.57788 \\
Durbin-Watson stat & 1.470626 & & & \\
\hline
\end{tabular}

Berdasarkan Tabel 2, hasil analisis menunjukkan dengan alfa 5\%, ditemukan bahwa return Bitcoin dipengaruhi oleh harga penutupan sebelumnya yaitu pada Bitcoin ln price $e_{\mathrm{t}-1}$. Namun pada variabel harga emast-1, harga Dollar Index $\mathrm{t}_{\mathrm{t}-1}$ dan harga $\mathrm{IHSG}_{\mathrm{t}-1}$ tidak mempengaruhi return Ethereum. Selain itu, penelitian ini mengikuti model GARCH, dibuktikan dengan hasil GARCH (-1) kurang dari 5\%. 
Table 3. GARCH dengan variance equation dalam Bitcoin

\begin{tabular}{|c|c|c|c|c|}
\hline Variabel & Coefficient & Std. Error & z-Statistik & Probabilitas \\
\hline $\mathrm{C}$ & $4.95 \mathrm{E}-05$ & $8.54 \mathrm{E}-05$ & 0.579068 & 0.5625 \\
\hline Bitcoin (BTC) ln price t-1 & 0.117083 & 0.001680 & 69.69001 & 0.0000 \\
\hline Emas $(\mathrm{XAU})$ price $_{\mathrm{t}-1}$ & $9.17 \mathrm{E}-07$ & $1.05 \mathrm{E}-05$ & 0.087630 & 0.9302 \\
\hline Dollar Index (DXY) price ${ }_{t-1}$ & $1.09 \mathrm{E}-05$ & 0.000244 & 0.044875 & 0.9642 \\
\hline IHSG price $_{t-1}$ & $-2.56 \mathrm{E}-07$ & $1.94 \mathrm{E}-06$ & -0.131885 & 0.8951 \\
\hline \multicolumn{5}{|l|}{ Variance Equation } \\
\hline $\mathrm{C}$ & $3.54 \mathrm{E}-07$ & $5.64 \mathrm{E}-11$ & 1.724935 & 0.0101 \\
\hline $\operatorname{RESID}(-1)^{\wedge} 2$ & 0.150000 & 0.037855 & 12.90992 & 0.1493 \\
\hline GARCH(-1) & 0.600000 & 0.016152 & 43.90923 & 0.0000 \\
\hline EXP(XAU price $\left.{ }_{t-1}\right)$ & 0.000000 & $1.18 \mathrm{E}-05$ & 0.000000 & 1.0000 \\
\hline EXP (DXY price $\left._{t-1}\right)$ & 0.000000 & $6.06 \mathrm{E}-05$ & 0.000000 & 1.0000 \\
\hline EXP (IHSG price $\left.{ }_{t-1}\right)$ & 0.000000 & $2.93 \mathrm{E}-06$ & 0.000000 & 1.0000 \\
\hline R-squared & 0.990506 & \multicolumn{2}{|c|}{ Mean dependent var } & 0.000380 \\
\hline Adjusted R-squared & 0.990440 & \multicolumn{2}{|c|}{ S.D. dependent var } & 0.006113 \\
\hline S.E. of regression & 0.000598 & \multicolumn{2}{|c|}{ Akaike info criterion } & -11.68614 \\
\hline Sum squared resid & 0.000254 & \multicolumn{2}{|c|}{ Schwarz criterion } & -11.60957 \\
\hline Log likelihood & 4201.481 & \multirow{2}{*}{\multicolumn{2}{|c|}{ Hannan-Quinn criter. }} & -11.65657 \\
\hline Durbin-Watson stat & 2.087506 & & & \\
\hline
\end{tabular}

Berdasarkan Tabel 3, hasil analisis menunjukkan bahwa dengan alfa 5\% volatilitas ditemukan Bitcoin tidak dipengaruhi oleh variabel lainnya namun dipengaruhi oleh harga dari Bitcoin sendiri yaitu harga $\ln _{t-1}$.

Table 4. GARCH dengan variance equation dalam Ethereum

\begin{tabular}{|c|c|c|c|c|}
\hline Variabel & Coefficient & Std. Error & z-Statistik & Probabilitas \\
\hline $\mathrm{C}$ & 0.000482 & 0.000823 & 0.585905 & 0.5579 \\
\hline Ethereum (ETH) ln price $_{t-1}$ & 0.200461 & 0.015164 & 13.21949 & 0.0000 \\
\hline Emas (XAU) price ${ }_{t-1}$ & $2.29 \mathrm{E}-05$ & 8.94E-05 & 0.256650 & 0.7974 \\
\hline Dollar Index (DXY) price t- & 0.000729 & 0.002135 & 0.341610 & 0.7326 \\
\hline IHSG price $_{t-1}$ & $9.68 \mathrm{E}-07$ & $1.53 \mathrm{E}-05$ & 0.063289 & 0.9495 \\
\hline \multicolumn{5}{|l|}{ Variance Equation } \\
\hline $\mathrm{C}$ & $1.96 \mathrm{E}-05$ & $1.02 \mathrm{E}-05$ & 1.914929 & 0.0555 \\
\hline $\operatorname{RESID}(-1)^{\wedge} 2$ & 0.150000 & 0.073852 & 2.031077 & 0.0422 \\
\hline GARCH(-1) & 0.600000 & 0.170765 & 3.513600 & 0.0004 \\
\hline $\operatorname{EXP}\left(X A U\right.$ price $\left._{t-1}\right)$ & 0.000000 & $1.13 \mathrm{E}-05$ & 0.000000 & 1.0000 \\
\hline EXP (DXY price t $\left._{-1}\right)$ & 0.000000 & 0.000130 & 0.000000 & 1.0000 \\
\hline EXP (IHSG price ${ }_{t-1}$ ) & 0.000000 & $3.16 \mathrm{E}-06$ & 0.000000 & 1.0000 \\
\hline R-squared & 0.911732 & \multicolumn{2}{|c|}{ Mean dependent var } & 0.001276 \\
\hline Adjusted R-squared & 0.911112 & \multicolumn{2}{|c|}{ S.D. dependent var } & 0.014895 \\
\hline S.E. of regression & 0.004441 & \multicolumn{2}{|c|}{ Akaike info criterion } & -7.747780 \\
\hline Sum squared resid & 0.014021 & \multicolumn{2}{|c|}{ Schwarz criterion } & -7.671210 \\
\hline Log likelihood & 2789.579 & \multirow{2}{*}{\multicolumn{2}{|c|}{ Hannan-Quinn criter. }} & -7.718214 \\
\hline Durbin-Watson stat & 1.538048 & & & \\
\hline
\end{tabular}

Berdasarkan Tabel 4, dengan alfa 5\% menunjukkan bahwa volatilitas Ethereum tidak dipengaruhi oleh variabel lainnya namun dipengaruhi oleh harga dari Ethereum sendiri yaitu harga $\ln _{t-1}$.

Hasil analisis menunjukkan harga Bitcoin dipengaruhi oleh harga masa lalu dari Bitcoin dan emas. Hasil tersebut dibuktikan dengan nilai probabilitas pada harga masa lalu dari Bitcoin dan emas dalam mean equation yang lebih kecil dari 5\%. Namun pada volatilitas Bitcoin hanya dipengaruhi harga masa lalu dari Bitcoin saja. Sedangkan variabel lainnya tidak mempengaruhi Bitcoin. Hasil tersebut dibuktikan dengan nilai probabilitas dari Bitcoin dalam variance equation. Selain itu, dengan probabilitas GARCH( -1$)$ ditemukan bahwa Bitcoin mengikuti pola GARCH.

Dengan alfa 5\%, mendapatkan hasil harga Ethereum dipengaruhi oleh harga masa lalu hanya dari Ethereum saja. Hasil tersebut dibuktikan dengan nilai probabilitas pada harga masa lalu dari Ethereum dalam mean equation. Hasil yang sama ditemukan dalam analisis volatilitas Ethereum. Dalam volatilitas 
Ethereum dipengaruhi harga masa lalu dari Ethereum saja. Sedangkan variabel lainnya tidak mempengaruhi Ethereum. Hasil tersebut dibuktikan dengan nilai probabilitas dari Ethereum dalam variance equation. Selain itu, dengan probabilitas GARCH(-1) ditemukan bahwa Ethereum mengikuti pola GARCH.

Dari hasil diatas menunjukkan hasil analisis mean equation dan variance equation adalah konsisten. Hal ini menunjukkan bahwa terdapat robus. Sehingga hasil diatas dapat dipercaya. Hasil penelitian juga menunjukkan bahwa pasar cryptocurrency tidak efisien karena dipengaruhi harga masa lalu dan tidak berjalan secara acak.

\section{Simpulan dan Saran}

Penelitian ini bertujuan untuk memahami analisis volatilitas cryptocurrency dengan menggunakan emas, Dollar Index, dan Indeks Harga Saham Gabungan (IHSG) dengan variabel penjelas dan mean equation (1) variance equation (2). Hasil dari mean equation menunjukkan bahwa harga Bitcoin dipengaruhi oleh harga masa lalu dari Bitcoin dan emas, sedangkan variabel lain tidak mempengaruhi harga Bitcoin. harga Ethereum hanya dipengaruhi oleh harga masa lalu dari Ethereum sedangkan variabel lainnya tidak mempengaruhi. Oleh karena itu, pasar cryptocurrency bukan sebagai pasar efisien karena dapat dianalisis dari harga masa lalunya. Selain itu hasil dari variance equation menunjukkan bahwa volatilitas Bitcoin hanya dipengaruhi oleh harga masa lalu dari Bitcoin sendiri dan tidak dipengaruhi oleh variabel-variabel lain. Hasil yang sama didapatkan dalam volatilitas Ethereum yang dipengaruhi oleh harga masa lalu dari Ethereum dan tidak dipengaruhi oleh variabel-variabel lainnya. Sehingga dalam melakukan investasi pada cryptocurrency khususnya Bitcoin dan Ethereum investor dapat melakukan analisis pada harga sebelumnya.

Penelitian ini memiliki beberapa keterbatasan yaitu penelitian ini hanya mengarah pada Ethereum dan Bitcoin sehingga pada penelitian mendatang dapat menganalisis instrument lainnya selain Bitcoin dan Ethereum.

\section{Daftar Rujukan}

Aulia, M. R. (2018). Pro dan Kontra Bitcoin: Analisis Pengaruh Perkembangan Bitcoin, Performa Flat Money dan Sistem Kelola Negara. Universitas Lampung, 10(2), 1-15.

Auso, Asep Zaenal, Elsa Silvia Nur Aulia. 2018. Teknologi Cryptocurrency Bitcoin untuk Investasi dan Transaksi Bisnis Menurut Syariat Islam. Jurnal Sosioteknologi | Vol. 17, No 1, Hal. 74-92. Tersedia Pada: http://journals.itb.ac.id/index.php/sostek/article/view/7365/3177.

Bhosale, J., \& Mavale, S. (2018). Volatility of select Crypto-currencies : A comparison of Bitcoin, Ethereum and Litecoin. Annual Research Journal of SCMS, Pune, 6(March), 132-141.

Connor, F. A. O., Lucey, B. M., Batten, J. A., \& Baur, D. (2015). The Financial Economics of Gold - A Survey. International Riview of Financial Analysis, July 2018. https://doi.org/10.1016/j.irfa.2015.07.005

Dannen, C. (2017). Introducing ethereum and solidity: Foundations of cryptocurrency and blockchain programming for beginners. In Introducing Ethereum and Solidity: Foundations of Cryptocurrency and Blockchain Programming for Beginners. Apress. https://doi.org/10.1007/978-1-4842-2535-6

Dyhrberg, A. H. (2015). Bitcoin, gold and dollar - A GARCH volatility. Finance Research Letters, 000, 1-8. https://doi.org/10.1016/j.frl.2015.10.008

Dynand, M. R., \& Kartawinata, B. R. (2018). Comparative Analysis of Cryptocurrency in Forms of Bitcoin, Stock, and Gold as Alternative Investment Portfolio in 2014 - 2017 Analisis Perbandingan Cryptocurrency Bitcoin, Saham dan Emas sebagai Alternatif Portfolio Investasi Tahun 2014 2017. Jurnal Sekretaris \& Administrasi Bisnis, II(2), 38-51.

Eli, D. (2008). Cryptocurrency. The New Palgrave: A Dictionary of Economics, March, 1-5. https://doi.org/10.1057/978-1-349-95121-5. 
Habashi, F. (2017). Gold - An Historical Introduction. December 2016. https://doi.org/10.1016/B978-0444-63658-4.00001-3

Hartati, \& Saluza, I. (2017). Aplikasi GARCH dalam Mengatasi Volatilitas Pada Data Keuangan. Jurnal Matematika, 7(2), 107. https://doi.org/10.24843/jmat.2017.v07.i02.p87

Lydianita, H. (2011). Analisis Faktor - Faktor yang Mempengaruhi Volatilitas Harga Saham.

Nastiti, K. L. A., \& Suharsono, A. (2012). Analisis Volatilitas Saham Perusahaan Go Public dengan Metode ARCH-GARCH. Jurnal Sains Dan Seni ITS, 1(1), 259-264.

Nurmapika, Ryafini, Nurliza, Imelda. 2018. Analisis Volatilitas Harga Komoditas Pangan Strategis Di Provinsi Kalimantan Barat (Studi Kasus Pasar Flamboyan Pontianak). Jurnal Social Economic of Agriculture, Volume 7, Nomor 1, Hal. 41-53. Tersedia Pada: http://jurnal.untan.ac.id/index.php/jsea/article/view/30751.

Pangesti, A. (2009). Pengaruh Nilai Tukar Rupiah dan Indeks Harga Saham Gabungan Terhadap Indeks Harga Saham Sektor Keuangan.

Rahayu, M. F., Chang, W.-I., \& Anindita, R. (2015). Volatility Analysis and Volatility Spillover Analysis of Indonesia's Coffee Price Using Arch/Garch, and Egarch Model. Journal of Agricultural Studies, 3(2), 37. https://doi.org/10.5296/jas.v3i2.7185

Robiyanto, \& Pangestuti, I. R. D. (2018). Weak form market efficiency analysis in the cryptocurrency market. Jurnal of Economic and Bisnis, 2(c), 124-128.

Robiyanto, R. (2018). Gold VS bonds: What is the safe haven for the indonesian and Malaysian capital market? Gadjah Mada International Journal of Business, 20(3), 277-302. https://doi.org/10.22146/gamaijb.27775

Robiyanto, R., Susanto, Y. A., \& Ernayani, R. (2019). Examining the day-of-the-week-effect and the-monthof-the-year-effect in cryptocurrency market. Jurnal Keuangan Dan Perbankan, 23(3), 361-375. https://doi.org/10.26905/jkdp.v23i3.3005.

S. Dimas Okky, \& Setiawan. (2012). Pemodelan Indeks Harga Saham Gabungan ( IHSG ), Kurs , dan Harga Minyak Dunia dengan. Jurnal Sains Dan Seni ITS, 1(1), 1-6.

Shen, Z. (2014). How the US Dollar Index Affects Gold Prices. September. https://webcache.googleusercontent.com/search?q=cache:kAFsdBGe1fwJ:https://www.askfinan cials.com/pdf/knowledgepanel/Dollar\%2520Index\%2520The\%2520Bull\%2520market\%2520no\%2520one\%2520wants \%2520January\%25202017.pdf $+\& \mathrm{~cd}=12 \& \mathrm{hl}=\mathrm{en} \& \mathrm{ct}=\mathrm{clnk} \& \mathrm{gl}=\mathrm{id}$

Wood, G. (2014). Ethereum: a secure decentralised generalised transaction ledger.

Yohandi, A., Trihastuti, N., \& Hartono, D. (2017). Implikasi yuridis penggunaan mata uang virtual bitcoin sebagai alat pembayaran dalam transaksi komersial (studi komparasi antara IndonesiaSingapura). Diponegoro Law Journal, 6, 1-19. https://doi.org/10.1017/S0269888907001014 